\title{
ORGANIZATION AND AVAILABILITY OF INFORMATION IN THE PUBLIC ACADEMIC SPACE OF HIGHER EDUCATION WEBSITES
}

\author{
Danijela Pongrac ${ }^{1}$ and Mihaela Banek Zorica ${ }^{2}$ \\ ${ }^{I}$ Zagreb University of Applied Science, Vrbik 8, 10000 Zagreb, Croatia \\ ${ }^{2}$ Faculty of Humanities and Social Sciences, University of Zagreb, Ivana Lucica 3, 10000 Zagreb, Croatia
}

\begin{abstract}
A key component for the quality of knowledge management at a higher education institution is understanding its mechanisms of the organization and dissemination of information. This research evaluates public websites of academic space in the domain interest of faculty staff, concerning the possibilities of finding and availability of information, how the data was structured, and diffusion of information. A qualitative and quantitative evaluation of criteria codification, abstraction, and diffusion was made. The template for the analysis of the website was made according to the analysis of previous research, with the necessary contextual adaptation. The obtained results enable an analysis of the information space, on a public website, revealing the quantity and quality of information relevant to the areas of interest in the academic sphere. Based on obtained data we identify factors for an effective flow of codified information on the higher education website. This paper is part of a broader research, which determines the mechanisms of information diffusion through an academic institution according to the Information Space model.
\end{abstract}

\section{KEYWORDS}

HE Website, Diffusion, Codification, Abstraction

\section{INTRODUCTION}

Higher education institutions are organizations made up of experts from different fields who contribute with specific knowledge and experience, to create and preserve knowledge. Knowledge management thus becomes an essential determinant in higher education, as it ensures the efficient flow of knowledge between people and processes, which affects improving overall efficiency and effectiveness. In this context, the question of how to achieve greater employee efficiency through better connections in public and private academic space, either individually or with other participants, stands out. Given the huge production of information and knowledge in higher education institutions, it is necessary to meet a dynamic adjustment of timeliness, relevance and availability of the same. The question may be asked whether there is a sufficient amount of relevant information that is available through various forms of transmission. According to the author Boisot, the transmission of information is positively related to codification and abstraction, and negatively to the size of the target population (Boisot, 1995). Thus, codification and abstraction represent a common form of cognitive strategy for efficient access and processing data. Higher education websites are the starting point for accessing, communicating and disseminating information both to the public and to all those who make up the higher education system. We can view it as an explicit academic space of information, thus its role has multiple meanings, as a starting point for all stakeholders, from students and teachers, through administration and management, to the public. Within this context, this paper makes a qualitative and quantitative evaluation of the prerequisites for the information diffusion on a public website higher education institution.

Diffusion, i.e. dissemination, of information as its goal, toward the user, is to find relevant and usable knowledge. In the context of the higher education website, this refers, among other things, to easy navigation around the site, either through content categories or through internal links, which ensures a better user experience, longer visitor retention and greater security in identifying relevant institutional information. The prerequisites for the diffusion of information according to Boisot's Information Space model are codification and abstraction. Codification ensures the structuring of data through categorization and classification, i.e. it 
provides form, while abstraction, as a cognitive strategy, is related to the creation of knowledge through analysis and understanding, to arrive at generalization. Diffusion is associated with the expansion of access and transmission of previously abstracted information, where information and communication technologies ensure, through access and transmission, the smooth flow of information (Boisot, 1995; Dalkir, 2011). Regarding Information Space model we have listed two assumptions, which did not been tested in the context of academic space in previous research. The first assumption is that a high level of codification and abstraction of information in space ensures greater diffusion, while the second states that the larger the target population, the weaker the diffusion, i.e. the information is less widespread in space. Research determines the mechanisms of information diffusion through the organization. Given the openness of the higher education website to various users, as well as the large amount of information content, the level of data structure and content abstraction affects the website quality. Researching the structure and abstraction of data we can get an answer to whether diffusion has been achieved and to what extent.

This paper present a review of previous research regarding quality, usability and diffusion of data within higher education website, where we have identified 32 characteristics, for 10 indicators within 3 main criteria (codification, abstraction and diffusion). The total points values of all reviewed categories/menu on the website are given through 3 main criteria tables. Ultimately overall success points of all 3 criteria are evaluated trough numerical scale, in the whole sample, as well as for each university. Therefore, analysis of higher education public website answers questions about the type of information available, the way it is organized and diffused. In doing so, we also investigate the quantity and quality of information relevant to faculty staff.

The conducted research will determine the sustainability of the Information Space model in the higher education environment. It should also be noted that no research has been found in the literature that confirms the model in this way. A particular contribution to the extension of the existing model will be in identifying factors for the effective flow of codified information for employee performance purposes.

The main goal of the paper is the intention to confirm the model of the Information Space through practice, specifically in the analysis of higher education public websites.

\section{LITERATURE REVIEW: EVALUATIONS OF HIGHER EDUCATION WEBSITES}

To conduct this research, various methodologies and analyses have been reviewed, which have so far been proposed through the scientific literature, to conduct a higher education website analysis according to the goals and criteria of this research. In website research, a large number of them relate to determining the framework for assessing website quality in general (Aladwani and Palvia, 2002; Barnes and Vidgen, 2003; Kim and Kuljis 2010; Rocha 2012), as well as those in the context of higher education (Tate, et al., 2007; Carlos and Rodrigues, 2012; Al-Debei, 2013; Leach and Ramachandran, 2018). Through the mentioned studies, quality factors have been proposed that are examined through survey evaluations, from student population.

In the field of higher education website quality, great attention is paid to the aspect of usability, which is assessed as the most important factor influencing the quality of the site. Usability testing refers to the evaluation of a product or service by testing with representative users. Automated web tools are used to assess and research usability aspects (Kaur, et al., 2016), user surveys according to different models of website quality evaluation (Aladwani and Palvia, 2002; Barnes and Vidgen, 2003; Tate, et al., 2007; Carlos and Rodrigues, 2012; Elangovan, 2013), and experimental research on user behavior when searching for information, i.e., automated web evaluation (Undu and Akuma, 2018).

Author Pinto, et al., $(2007,2009)$ investigate quality indicators on a particular topic on the public websites of Spanish universities, where they also include the dimension of information diffusion. Through these two studies, a series of evaluation criteria and indicators has been developed, which enable the understanding of how information is disseminated through public universities and what its quality is. One of the initial conclusions is that there are two approaches to website analysis, the first refers to webometrics, i.e. analysis of various measurements, and the second to quality indicators, and these two approaches are intertwined in the analysis, depending on the purpose of research. Both studies on the dissemination and impact of digital information in academia (Pinto, et al., 2007, 2009) examine the following categories: Visibility, Authority, Update, Accessibility, Diffusion / Dissemination, Quality Policy, and Navigation. The framework for collecting data on codification, abstraction and diffusion of information was taken from the mentioned research. 
No available research was found that is oriented toward the faculty staff in the context of usability and quality of the site, the student population is most surveyed, because it is common opinion that the higher education public website should first satisfies future and current students. In doing so, one forgets that the academic web space is by its nature complex because it satisfy different functionalities for a set of heterogeneous users. To research a higher education website from the perspective of faculty staff, it is necessary to determine the relevant content for this group of users. Authors Sugiyanto, et al., (2016) in their research states that from the perspective of teachers, the website should disseminate the following information: achievements of completed research projects, changes in educational programs, research data, providing services to the wider community, presentations of research topics for students and companies.

As this research seeks to emphasize faculty staff, the information available on the public portal is viewed through the perspective of teachers, where the type of relevant information for faculty staff stands out as an important issue. The author Saračević (2007) in a comprehensive review of relevance research states that there are a large number of studies, criteria, measures and methods that have been used, but none of them are standardized, there are even significant differences. The survey extracts relevance indicators from several previous surveys, based on which users direct their search on the web. The most common category of relevance is related to the issue of content, and the indicators relate to: topic, quality, depth, scope, age of information, processing and clarity. When analyzing the content of the website and determining the relevance, it is necessary to investigate the above indicators on the characteristics of the requested information.

Generally in the context of higher education, information and knowledge are created at different levels (academic, organizational, personal and group), and through different forms (facts, concepts, methodologies, predictions), so it can appear in a different form at each level (Wiig, 1993). Thus, categories from perspective of a personal user are often determined, rather than by attributes of information and knowledge. In order for information to have an efficient flow the basic setting is a common language. By common language we mean a common vocabulary and understanding of its terminology, and the basic matching of categories (Lambe, 2007).

According to the author Pinto, et al., (2007) the quality of information can have different dimensions of evaluation depending on the research approach or research area. That is, as Pinto concludes, the criteria and indicators used in determining the quality of a website depend on the information to be obtained from such an analysis, as well as on the characteristics of the website being researched.

\section{METHODOLOGY}

This study is part of a larger research using dual methodology through qualitative and quantitative analysis, which is ongoing. With descriptive method we explain the basic starting points of the work, and the elements important for the organization of information and knowledge. The sample selected public Polytechnics that cover the fields of social and technical sciences, of which there are 7 in Croatia. School names have been replaced by V1 to V7 (Table 5). Using the method of direct insight with the help of data collection tools, the structure and distribution of the content on the Polytechnic public website was investigated. The following content categories were selected as pages that have relevant information for teaching staff: About us, Erasmus, Projects / Science and Research, Tenders, and Quality / Lifelong. The data collection tool was a template for researching data structuring and diffusion. For its development, possible indicators from the analysis of previous research were first collected (Pinto, et al., 2007, 2009) and adapted to the context of this research, those who best present the structure and distribution of information were selected.

Based on the collected quantitative data from the higer education public website, in this case Polytechnic, a qualitative evaluation of codification and abstraction criteria was conducted, as the basic prerequisites for the diffusion of information. The measure of the representation of individual criteria was adopted in accordance with the initial assumptions and on the basis of the Information Space model (Boisot, 1995).

Codification criterion - We can say that we achieve codification through form, thus it includes indicators of categorization and classification. The aim was to determine whether there is a clear menu structure that the user can choose from, and how many subcategories are present, in terms of ensuring visibility, optimization and focus. According to Boisot (1995), by reducing the number of categories, we also achieve a better function of abstraction. 
Abstraction criterion - We observe abstraction in the function of cognitive strategy, and evaluate the characteristics of organization and thematic uniqueness of content, to achieve the integrity of information. Also, the clarity of the text as well as the use of the same terms for a particular meaning ensures consistency and speeds up the transmission of information

Diffusion criterion - This criterion is the most important in this research, therefore it has the largest number of characteristics through which it is desired to determine the expansion of access to information and its transmission. The selected characteristics that assess the achievement of the diffusion criteria relate to the ways and possibilities of searching for information, the achieved relevance of the query, and the ease and simplicity of navigating through navigation and links.

\subsection{Method of Implementation}

The analysis of selected Polytechnics was made in November 2019. A pre-survey was first conducted at two Polytechnics that have all the required content categories, to determine if a change in the number of indicators and characteristics was needed. Data collection process was made through a template based on the existence or nonexistence of the required characteristic, where 1 is assigned for the existence and 0 for the nonexistence. Finally, the total points number of characteristics found for each indicator or criterion was calculated. This process of collection and processing has been implemented through the mentioned research by Pinto et al., (2007, 2009). The results show average value of the existence of criteria by an individual Polytechnic, as well as the achievement of individual characteristics, indicators and criteria on the entire sample. Based on the obtained mean values of the criteria, a numerical scale (Table 1) from 1 to 5 was determined to assess the measure of meeting the criteria, i.e. how much they are achieved in relation to the whole sample as well as to each Polytechnic.

Table 1. Scale for assessing the fulfillment of criteria

\begin{tabular}{|c|l|}
\hline Scoring limit for a scale from $\mathbf{1}$ to $\mathbf{5}$ & Assessment of the fulfillment of all criteria \\
\hline $0-32$ & Completely unsatisfactory \\
\hline $33-64$ & Mostly unsatisfactory \\
\hline $65-96$ & Moderately satisfactory \\
\hline $97-128$ & Very satisfactory \\
\hline $129-160$ & Completely satisfactory \\
\hline
\end{tabular}

The total points number of characteristics is 32 , of which 7 are related to the criterion of codification, 5 to the criterion of abstraction and 20 to the criterion of diffusion, thus the maximum number of points that can be achieved is 160 (Table 1), i.e. 35 for codification, 25 for abstraction and 100 for diffusion, since 5 category /menus on the web site are being viewed. This means that 7 criterion of codification multiplied by 5 menus on web site give max points number of 35 , and so on. Also, for each criterion the number of characteristics or indicators on the entire sample is shown, as well as the percentage of realization of that criterion.

\section{RESULTS AND DISCUSSION}

According to the information space model, one of the prerequisites for abstraction is the reduction of the number of categories, those pages with a larger number of categories have less abstraction, which makes it harder to find specific information because the diffusion is smaller. More and better structured data accelerates the transmission and diffusion of information. The categories / menu that we can consider basic, because they are represented on all home pages, refer to information about the Polytechnic institution and to future and current students. Such results correspond to the results obtained in other studies that investigated the representation of certain content on the websites of higher education institutions for all stakeholders. However, in practice, university websites are mainly focused on three groups: current and potential students, and faculty staff (Tate, et al., 2007). Research dealing with the quality of content representation on higher education website is questioned mainly within the student population (Carlos and Rodrigues, 2012; Al-Debei, 2013; Elangovan, 2013), while only some include faculty staff (Sugiyanto et al., 2016). 


\subsection{Codification and abstraction}

Each criterion has indicators with its own characteristics. If the results are observed according to a particular characteristic, it can be determined in which area of content presentation improvement is needed. For each characteristic, the maximum number of points for the whole sample is 35 , given the 5 categories $/ \mathrm{menu}$ reviewed, which are relevant to faculty staff, and a sample size of 7 Polytechnics. The codification criterion is determined through the indicators of categorization and classification of data, through 7 characteristics (Table 2 ). The table 2 shows that the codification criterion in the entire sample has the lowest achievement of $48.57 \%$, with the weakest characteristics of the classification of documents (11 points out of 35) and a large number of subcategories.

Table 2. Data codification

\begin{tabular}{|c|c|c|c|c|}
\hline Criterion & Indicator & Characteristic & Points & Median \\
\hline \multirow{7}{*}{ 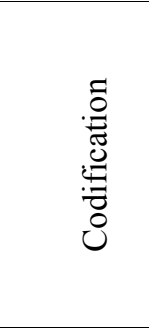 } & \multirow[b]{2}{*}{ Categorization } & Clear category structure & 17 & \multirow[b]{2}{*}{14,5} \\
\hline & & $\begin{array}{l}\text { The number of subcategories does not exceed } 5 \text { / or / } \\
\text { there are no categories }\end{array}$ & 12 & \\
\hline & \multirow{5}{*}{ Classification } & The information is arranged according to thematic areas & 17 & \multirow{5}{*}{17} \\
\hline & & The information is grouped within thematic areas & 14 & \\
\hline & & The lower categories inherit the features of the higher & 20 & \\
\hline & & Existence of classified documents & 11 & \\
\hline & & Links to documents & 28 & \\
\hline \multirow{2}{*}{\multicolumn{3}{|c|}{$\begin{array}{r}\text { Overall } \\
\%\end{array}$}} & 119 & \\
\hline & & & 48,57 & \\
\hline
\end{tabular}

When looking for information at multiple universities, misunderstandings can occur because the categories/menu have a larger number of subcategories, which are not located within the same category, thus reducing ease of use. Also, information related to the same thing (need not be identical) is found in multiple thematic areas, leading to general fragmentation and frustration of users in wanting to find complete information on a particular thing. Boisot (1995) emphasizes that the higher the degree of coding, the less data is needed to describe the subject, and therefore holds that codification creates perceptual and conceptual categories by facilitating the classification of phenomena.

The abstraction criterion is determined through indicators of content, comprehensibility and consistency of terminology, through five characteristics (Table 3). This criterion has a higher overall percentage (69.14\%) compared to the codification. All indicators and their characteristics have more than half the number of points, out of a possible 35 .

Table 3. Content abstraction

\begin{tabular}{|c|c|c|c|c|}
\hline Criterion & Indicator & Characteristic & Points & Median \\
\hline \multirow{5}{*}{ 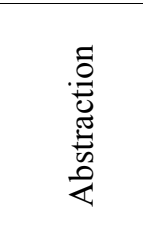 } & \multirow{2}{*}{ Content } & Thematically unique & 25 & \multirow{2}{*}{22} \\
\hline & & Organized & 19 & \\
\hline & \multirow{2}{*}{ Comprehensibility } & Clearly written & 28 & \multirow{2}{*}{25} \\
\hline & & Synthesis / comprehensive & 22 & \\
\hline & $\begin{array}{l}\text { Consistency of } \\
\text { terminology }\end{array}$ & The same terms are used in each category & 27 & 27 \\
\hline & & Overall & 121 & \\
\hline & & $\%$ & 69,14 & \\
\hline
\end{tabular}

The abstraction criterion has the highest percentage of representation within the sample of $69.14 \%$, which mostly refers to the content value of the texts, comprehensibility and the use of consistent terminology. It is the characteristics of the clarity of the text and the use of the same expressions within the categories that contain the highest number of points for this criterion. A higher level of abstraction, where coding has its place, involves a deeper insight and understanding of phenomena and things (Boisot, 1995). 


\subsection{Diffusion}

As the emphasis in this research is on diffusion, the number of characteristics of all indicators is higher than in the previous two categories and amounts to 20 (Table 4). The results of this criterion indicate that highest score has Navigation (Median 33) and Accessibility (Median of 25.5), thus complementing these two indicators. The lowest score has the Analysis of link loading from Google search, i.e. the characteristics of the relevance of the results, (Median 12). Indicators related to Links and Events have average values (Median 18). The total percentage of this criterion is $55.71 \%$, which corresponds to the average of the realized values of the previous two criteria.

Table 4. Data diffusion

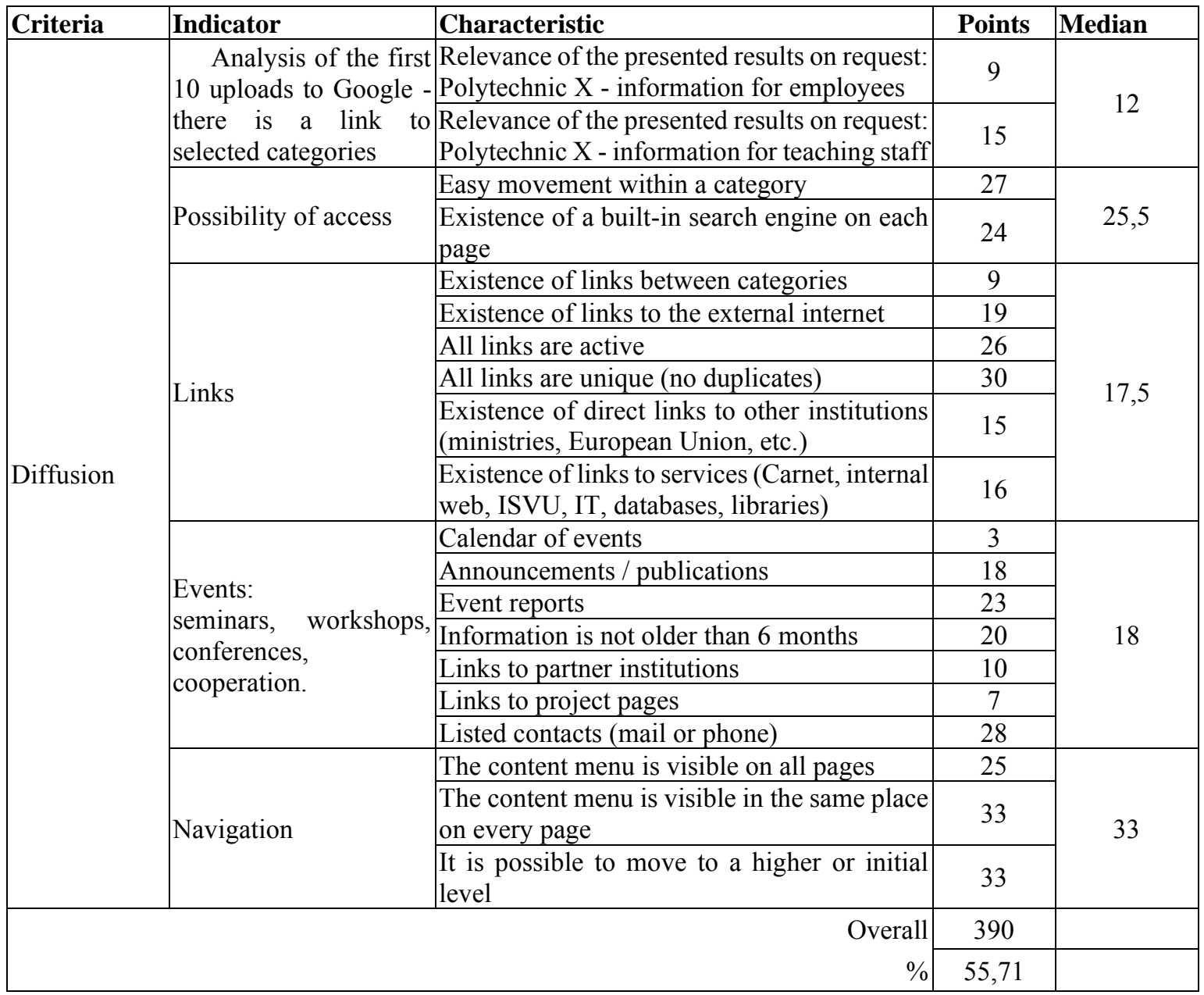

The diffusion criterion should reflect the functionality of the previous two criteria, i.e. the higher their values, the better the diffusion is represented. Characteristics that are for the most part present in the entire sample relate to the visibility of the category menu in the same place as passing through different pages of the place, and thus the possibility of moving to a higher or initial level of place. Navigation indicators are closely related to the technical part of the site, as they are mainly integrated as part of the finished application solution of the website. Navigation thus directly affects the characteristics of access capabilities because it allows easy navigation within the category, and the existence of a built-in search engine on each page can ensure the detection of related parts of the internal link structure, giving users better and faster access to relevant information. The worst score within the diffusion criteria relates to the relevance of the results obtained through the Google search engine. The query included the name of the school and "information for staff" or "information for teachers", and within the obtained result it is observed whether there is a link to any of the 
5 categories reviewed. Polytechnic V1 and V3 have the only links to 3 categories out of 5 , while the others have two or one. This result can be characteristic of insufficient page customization using the Search Engine Optimization tool. It is necessary to create an architecture that prioritizes the user experience.

Links, as well as various events have a half diffusion, as the best represented characteristics of the indicator "Links" are the absence of double links and the presence of active links. Among the features that are present to a small extent is the "Calendar of Events", which is foremost non-existent, although post-event reports are present. There are also not many links between categories, which is mitigated by page navigation, although links within the domain determine the contextual relevance of the topic and content. Due to announcements about various projects in which the institution participates, there are no links to project pages, which reduces the emphasis on users and recognition in the context of projects of wider social significance. The link shows the reputation of the institution, academic performance, information on the value, impact and usefulness of the higher education website. The more links there are, and the greater the visibility value of the website.

Finally, the overall assessment of the achieved criteria for the whole sample and individual Polytechnics, according to the scale from Table 1 , are shown in Table 6.

Table 5. Evaluation of the success of all criteria

\begin{tabular}{|l|l|l|l|l|l|}
\hline Criteria & Codification & Abstraction & Diffusion & $\begin{array}{l}\text { Total } \\
\text { points }\end{array}$ & Evaluation of all criteria \\
\hline $\begin{array}{l}\text { Max number of } \\
\text { points }\end{array}$ & $\mathbf{3 5}$ & $\mathbf{2 5}$ & $\mathbf{1 0 0}$ & $\mathbf{1 6 0}$ & \\
\hline Mean value & $\mathbf{1 7 , 0}$ & $\mathbf{1 7 , 3}$ & $\mathbf{5 5 , 7}$ & $\mathbf{9 0}$ & moderately satisfactory \\
\hline$V 4$ & 15 & 21 & 68 & 104 & very satisfactory \\
\hline$V 5$ & 21 & 23 & 60 & 104 & very satisfactory \\
\hline$V 6$ & 20 & 16 & 57 & 93 & moderately satisfactory \\
\hline$V 1$ & 24 & 16 & 51 & 91 & moderately satisfactory \\
\hline$V 2$ & 19 & 17 & 54 & 90 & moderately satisfactory \\
\hline$V 7$ & 12 & 18 & 55 & 85 & moderately satisfactory \\
\hline$V 3$ & 8 & 10 & 45 & 63 & mostly unsatisfactory \\
\hline
\end{tabular}

The results of the evaluation of all criteria, determined according to the scale of values from Table 1 for each polytechnic (V1 to V7) and for the entire sample, were sorted according to the total number of points achieved for all criteria (Table 5). Given the maximum number of points (160), the obtained mean value for the whole sample is 90 , which on a scale of 5 values corresponds to the grade "Moderately satisfactory". If codification and abstraction are conditions for diffusion, Polytechnics that have the highest sum of codification and abstraction by rank, according to the model assumptions, should be in the same rank of diffusion points. Of the 7 Polytechnics in the sample for 5 (V5, V6, V2, V7, V3) we can confirm that assumption.

Considering that the higher education website has become the main source of academic information for the outside world, it is increasingly important to achieve a recognizable and strong internet presence, as a portal for all stakeholders. In this sample, Polytechnic public websites are presented as a static information channel or information holder. It is unnoticeable that this is a door to all stakeholders, from students, academic staff, industry, partner institutions, parents, administration, as well as the community within which they operate.

\section{CONCLUSION}

Given the results obtained, and considering the limitations of the research, that is, the fact that the data were collected using a certain set of indicators, which are by no means the only possible, it can be concluded that the situation is not bad, but not too good. The overall mean average performance of all criteria for the whole sample is "Moderately satisfactory", or 56\%. Undoubtedly, improvements are needed to implement better ways of disseminating information to make it easily accessible and useful.

According to the Information Space model, and in order to better disseminate information, higher education websites must enable easy and fast finding of information through content categories or built-in search engines. This means ensuring the availability of different and relevant types of information, through quality content organization. In terms of their content and metadata, the documents must correspond to the category within 
which they are located, and it is desirable to avoid duplication of content. Better diffusion is also enabled by the amount of information available through different forms and types of content, which are expected to be understandable, timely, accurate, well-formed, in line with user expectations.

\section{REFERENCES}

Aladwania, A.M., Palvia, P.C. 2002. Developing and validating an instrument for measuring user-perceived web quality. Information \& Management. Vol. 39, pp. 467-476

Al-Debei, M.M. 2014. The quality and acceptance of websites: an empirical investigation in the context of higher education', Int. J. Business Information Systems, Vol. 15, No.2, pp.170 - 188. DOI: 10.1504/IJBIS.2014.059252

Barnes, S. J., Vidgen, R. T. 2003. Measuring Web Site Quality Improvements: a Case Study of the Forum on Strategic Management Knowledge Exchange. Industrial Management and Data Systems, 103 (5), pp. 297-309. ISSN 0263-5577.

Boisot, M.H., 1995. Information Space: A Framework for Learning in Organizations, Institutions and Culture, London; Routledge, London, England.

Carlos. V.S., Rodrigues, R.G., 2012. Web site quality evaluation in Higher Education Institutions. Procedia Technology. Volume 5, Pages 273-282.

Dalkir K., 2011. Knowledge Managment in Theory and Practice, MIT Press, Cambridge, Massachusetts, London.

Elangovan, N., 2013. Evaluating perceived quality of b-school websites. IOSR Journal of Business and Management (IOSR-JBM) e-ISSN: 2278-487X, p-ISSN: 2319-7668. Volume12, Issue 1, PP 92-102

Kaur, S., Kaur, K. and Kaur, P., 2016. Analysis of website usability evaluation methods. 3rd International Conference on Computing for Sustainable Global Development, New Delhi, India, pp. 1043-1046.

Kim, I., Kuljis, J., 2010. Applying content analysis to Web based content. Proceedings of the ITI 32nd International Conference on Information Technology Interfaces, Cavtat, Croatia, pp. 283-288.

Lambe P. 2007. Organizing Knowledge: Taxonomies, Knowledge and Organizational Effectiveness, Chandos Publishing, Oxford, London.

Leach, J., Ramachandran, S. 2018. Discourse Analysis of Higher Education Website Content. Language, Literature and Culture. Vol.1, No.1, pp.6-10.

Pinto, M., Sales, D., Doucet, A. et al. 2007. Metric analysis of the information visibility and diffusion about the European Higher Education Area on Spanish University websites. Scientometrics 72, 345-370.

Pinto, M., Guerrero, D., Fernández-Ramos, A. et al. 2009. Information provided by Spanish university websites on their assessment and quality processes. Scientometrics 81, 265.

Rocha, A., 2012. Framework for a global quality evaluation of a website, Online Information Review, Vol.36 Iss:3. pp.374-382.

Saračević, T., Relevantnost i kako se istraživala. 2007, Vjesnik bibliotekara Hrvatske, vol.50, n.1-2, pp.12-6.

Scharl, A., Bauer, C. 2000. Quantitative Evaluation of Web Site Content and Structure. Internet Research,10(1),31-44.

Sugiyanto, Siti Rochimah, Sarwosri. 2016. The Improvement of Software Quality Model for Academic Websites Based on Multi-Perspective Approach. Journal of Theoretical and Applied Information Technology, Vol.86. No.3. pp.464-471.

Tate, M., Evermann, J., Hope, B., Barnes, S. Perceived Service Quality in a University Web Portal: Revising the E-Qual Instrument. 2007 40th Annual Hawaii International Conference on System Sciences (HICSS'07), Waikoloa, HI, 2007, pp. $147 \mathrm{~b}-147 \mathrm{~b}$

Undu, A., Akuma, S., Investigating the Usability of a University Website from the Users' Perspective: An Empirical Study of Benue State University Website. International Journal of Computer and Information Engineering, Vol:12, No:10, 2018. pp. 922-929.

Wiig K.M. 1993. Knowledge management foundations: Thinking about thinking. How people and organizations create, represent and use knowledge, Schema Press, Ltd., Arlington, Texas, USA. 